\author{
Cadernos de \\ ESTUDOS LINGUIISTICOS - (59.1), Campinas, pp. 23-35 - jan./abr. 2017
}

\title{
NOMES INFINITOS: REFERÊNCIA E CONTEXTO
}

\author{
HERONIDES MOURA*
}

\begin{abstract}
RESUMO: Neste artigo, examino o conceito de nomes infinitos de Aristóteles (também chamados de nomes indefinidos). Proponho que a denotação dos nomes infinitos pode se tornar definida por meio de recursos contextuais. Esses recursos podem ser relações semânticas entre nomes e também enriquecimentos inferenciais com base no contexto de enunciação. Argumento, finalmente, que não há distinção entre nomes infinitos e nomes genuínos, pois ambos estão sujeitos à variação contextual, no processo de determinação da referência.
\end{abstract}

Palavras-Chave: Aristóteles; referência; contexto.

ABSTRACT: In this paper, I examine Aristotle's concept of infinite names, also called indefinite names. I propose that the denotation of infinite names can become defined through contextual devices. These contextual devices are semantic relations among nouns and also inferential enrichment grounded on utterance's context. Finally, I argue that there is no distinction between infinite names and true names, both of them being subjected to contextual variation, in the process of determining the reference. Keywords: Aristotle; reference; context.

\section{INTRODUÇÃO}

Neste trabalho, pretendo explorar o conceito de nomes infinitos, de Aristóteles, a fim de mostrar que, ao contrário do que ele indicava, estes nomes ${ }^{1}$ (substantivos) podem cumprir a função denominadora, desde que situados num contexto. O exemplo de nome infinito que vou examinar mais detidamente é o de não-ser humano. Aristóteles afirma que nomes como esse não têm uma referência definida e, como tal, não são nomes genuínos. Essa suposta incapacidade de denotar se justifica, na teoria aristotélica, em função do tipo de semântica que o filósofo adota. A semântica de Aristóteles está ancorada na visão de que uma expressão linguística dotada de significado está intimamente ligada a um referente, numa relação direta entre palavra e coisa.

Pretendo mostrar que, se assumimos que o significado é relacional e contextual, então os nomes infinitos são perfeitamente capazes de cumprir a função denominadora.

"Universidade Federal de Santa Catarina, Florianopolis (SC), Brasil. heronides@uol.com.br

${ }^{1}$ Vou usar o termo 'nome', em vez de substantivo. Ao longo do texto, a não ser que haja indicação ao contrário, tratarei de nomes comuns, e não nomes próprios. 
$\mathrm{Na}$ argumentação defendida aqui, a referência não é indicada com base apenas numa expressão linguística individual, fora do contexto. O contexto relevante para a denotação é definido, neste trabalho, como sendo de dois tipos: a) outras palavras do léxico de uma língua; b) enunciações contextualizadas das proposições.

A minha hipótese é que um nome infinito pode perfeitamente funcionar como um nome, desde que usado contextualmente, seja com base no contraste com outras palavras que restringem o seu significado indefinido, seja em proposições cujo enunciado se dá num contexto específico.

É importante observar que não se trata de cair no anacronismo de tentar impor a Aristóteles conceitos da semântica contemporânea. De fato, provavelmente uma solução contextual já se apresentasse como possível no âmbito da lógica aristotélica, como veremos na conclusão deste artigo. $\mathrm{O}$ meu objetivo é apenas explorar o conceito de nomes infinitos, a fim de lançar luz sobre o caráter relacional e contextual da determinação da referência nas línguas humanas.

O artigo está estruturado da seguinte forma: na seção 1, apresento o conceito de nomes infinitos em Aristóteles. Na seção 2, examino as razões que levam Aristóteles a propor que os nomes infinitos não são nomes genuínos. Na seção 3 , mostro como uma visão relacional e contextual das expressões linguísticas pode explicar como os nomes infinitos são capazes de cumprir a função denominadora. Finalmente, na última seção, apresento algumas conclusões.

\section{NOMES INFINITOS EM ARISTÓTELES}

Aristóteles define o conceito de nome infinito, ou nome indefinido, na obra De interpretatione $e^{2}$ " "não-homem' não é um nome; entretanto, tampouco há à disposição um nome pelo qual fosse preciso designá-lo; de fato, ele não é nem uma frase, nem uma negação; que seja, então, um nome indefinido" (De interpretatione, tradução de Angioni, 2006, p. 178). ${ }^{3}$

Vou usar o termo não-ser humano, ao invés do termo não-homem usado na tradução acima, pois Aristóteles usa o termo grego anthropos (homem) como um masculino genérico (sobre masculinos genéricos, conferir MADER; MOURA, 2015). O termo não-homem é, assim, ambíguo entre não-homem no sentido de negação do masculino, e não homem no sentido de negação do conceito mais amplo de ser humano, homens e mulheres incluídos. Aristóteles claramente estava pensando no segundo significado, mais genérico. Portanto, o meu uso do termo não-ser humano visa apenas eliminar essa ambiguidade do termo não-homem.

Ao invés de nome indefinido, vou adotar o termo nome infinito (cf. BOETHIUS, 20124, DE RIJK, 2002), que é outra denominação possível do

\footnotetext{
${ }^{2}$ Esta obra é normalmente citada com o título da tradução latina. Vou manter esta prática aqui.

${ }^{3}$ Vou usar, sempre que possível, as traduções em português de Angioni (2006). No entanto, este autor traduziu apenas trechos das obras citadas. Quando necessário, vou utilizar as traduções em inglês, reunidas no livro The Organon: The Works of Aristotle on Logic. (Jones, 2012).

${ }^{4}$ Boécio (na grafia em língua portuguesa) viveu de 480 a 524 da era cristã, e foi um importante tradutor e comentarista de Aristóteles.
} 
conceito aristotélico. O adjetivo infinito ressalta o caráter totalmente aberto, potencialmente infinito, da denominação envolvida.

São necessárias algumas observações iniciais antes de entrar na questão da impossibilidade, segundo Aristóteles, de considerar não-ser humano como um nome. Em primeiro lugar, o filósofo observa que não-ser humano não pode ser uma sentença negativa, apesar da presença da partícula negativa não. $\mathrm{O}$ termo não-ser humano não pode ser uma sentença porque não apresenta uma estrutura predicativa, a qual exige, na lógica aristotélica, a presença de um sujeito e um predicado.

O sujeito não se reduz a uma função gramatical, e traduções mais apropriadas do conceito aristotélico são subjacente (ANGIONI, 2006) ou substrato ${ }^{5}$ (DE RIJK, 2002). Estes termos correspondem melhor ao grego hypokeimenon, o qual "comporta sobredeterminação entre o sentido lógico e o sentido ontológico de coisa capaz de subsistir em si mesma" (ANGIONI, 2006, p. 116). Portanto, o conceito de hypokeimenon abarca diferentes níveis de aplicação: o gramatical, o lógico e o ontológico.

No plano ontológico, o conceito chave é "subsistir por si mesmo". Para Aristóteles, o termo não-ser humano não corresponde a uma substância capaz de subsistir por si mesma, ou, ao menos, não denota uma classe de coisas definida, que possa subsistir por si mesma. Por isso, não-ser humano não constitui uma verdadeira denominação. No entanto, mesmo possuindo um significado indefinido, o termo não-ser humano significa algo: tal termo significa alguma coisa indefinida (Whitaker, 1996, p.133). Nos termos de Aristóteles, em De Interpretatione: “... for I stated that the expression not-man was not a noun, in the proper sense of the word, but an indefinite noun, denoting as it does in a certain sense a single thing" (tradução de E.M. Edghill, em JONES, 2012).

Sendo assim, um nome indefinido pode entrar numa asserção, ocupando o lugar do hypokeimenon. Com isso, uma frase como $O$ não-ser humano é tem uma forma válida, e implica a afirmação da substância do termo não-ser humano, embora seja um tanto paradoxal a afirmação de uma coisa cuja denotação é indefinida. Há, assim, uma dualidade no funcionamento dos nomes indefinidos: eles não têm o caráter denominativo, mas ainda assim podem entrar em asserções, pois denotam uma única coisa (ainda que indefinida).

Como afirma Whitaker(1996), a ausência de significação definida levaAristóteles a negar a qualidade de nomes aos nomes infinitos: "We see in several passages that to signify is to signify some single thing. Even if some expression signifies more than one thing, still a different word could be assigned to each signification, so that each one would then only signify one thing (Meta. $1006^{\mathrm{a}}{ }_{34-\mathrm{b} 13}$ ); not to signify one thing is to signify nothing (Meta. $1006 \mathrm{~b}_{7}$ ). A name, then, must signify some definite, single thing" (WHITAKER, 1996, p. 63).

A função básica de um nome, na lógica aristotélica, é "to bring up a thing (in fact, a hypokeimenon) as an instance of the particular mode of being signified

\footnotetext{
${ }^{5}$ Substrate é o termo proposto por De Rijk (2002), na língua inglesa.
} 
by names" (DE RIJK, 2002, p. 206). Como o termo não-humano não é capaz de denotar uma entidade específica, ele não cumpre devidamente o papel do nome. Trata-se de um nome indefinido, e como tal não tem o poder de identificar um uma entidade ontológica definida, embora, formalmente, um nome infinito possa aparecer na posição de sujeito gramatical e lógico (hypokeimenon).

Um nome infinito como não-ser humano tem sua definição calcada no valor semântico de ser humano. A única indicação que temos para a interpretação de não-ser humano é a negação do termo ser humano. Mas, ao passo que o sentido de ser humano é definido, o termo não-ser humano aponta, indiscriminadamente, para todas as opções possíveis (pedras, casas, árvores, água, deuses etc). Ou seja, o termo positivo é definido e ancorado numa substância. O termo negativo é indefinido e não está ancorado em uma substância identificável. Dessa forma, não se consegue especificar, segundo Aristóteles, uma propriedade comum positiva que caracterize todos os seres que entram na categoria não-ser humano (WHITAKER, 1996, p. 64). A única característica de não-ser humano é a negação do humano. Aliás, isso gera a seguinte tautologia: não (ser humano é não-ser humano). Ou seja, é necessariamente falso que uma entidade que seja humana, seja ao mesmo tempo não-ser humano. Sobre esta necessidade lógica, Aristóteles afirma o seguinte na Metafísica, Livro 4:

\footnotetext{
Ora, se é verdadeiro dizer que algo é homem, é necessário que ele seja animal bípede (pois era isso que "homem" significava); e, se isso é necessário, não é possível que ele mesmo não seja animal bípede (pois era isso que "homem" significava); e, se isso é necessário, não é possível que ele mesmo não seja animal bípede (pois "ser necessário" significa isto: ser impossível não ser); portanto, não é possível que seja simultaneamente verdadeiro dizer que uma mesma coisa é homem e não é homem. (Aristóteles, Metafísica, tradução de ANGIONI, 2006, p. 175).
}

Em suma, um nome infinito é construído a partir de um nome definido. $\mathrm{O}$ termo ser humano pode perfeitamente cumprir a função de um nome. Como tal, pode entrar numa sentença afirmativa, na posição de predicado, inclusive. Quando um nome é predicado de "some 'thing', [x], whatever is said of that which is conveyed by this name will be said of [x] too. For instance, the name 'man' is correctely used of an individual human being, say, 'Socrates"' (DE RIJK, 2002, p. 380). Quer dizer, as propriedades associadas à classe dos seres humanos são afirmadas em relação ao indivíduo Sócrates. Note que, neste caso, o termo ser humano funciona como um predicado, e não como sujeito. Tendo em vista que o termo ser humano denota uma substância (no conceito aristotélico), então as propriedades dessa substância podem ser predicadas de um indivíduo particular. Mas que propriedades estão associadas ao termo não-ser humano? Assim, numa frase do tipo $x$ é ser humano, faz-se a predicação de propriedades (animal bípede, racional) de ser humano à entidade $x$, mas no caso de $x$ é não-ser humano, não temos uma propriedade comum que possa ser predicada de $x$.

A mesma dificuldade de aplicação dos nomes infinitos se encontra em frases como: O não-ser humano é branco. Para determinar o sentido (e a referência) dessa sentença seria preciso definir a entidade que funcionaria como substrato (hypokeimenon). Mas não se sabe o que vem a ser esse não-ser humano. 
A frase $O$ não-ser humano é branco teria de receber (na lógica aristotélica) uma reformulação do seguinte tipo: $x$ é não-ser humano e $x$ é branco. Falta, portanto, definir a natureza da entidade indicada pela variável $x$ (uma casa? Uma pedra? Uma árvore? Um deus?). Esse tipo de frase evoca outra situação na qual não se tem um substrato disponível.

Trata-se do caso da frase "o branco é lenho", a qual, embora tenha uma boa formação lógica e gramatical, carece também de uma reestruturação formal, para que possa receber uma interpretação válida (sempre de acordo com a lógica aristotélica). O nome "o branco" se aplica a um substrato $x$, o que leva à estrutura $x$ é branco. Por sua vez, este mesmo substrato $x$ está presente em $x$ é lenho. Ou seja, a forma lógica adequada da frase o branco é lenho seria: aquilo que é branco é lenho. Só por meio dessa reconstrução, a frase "o branco é lenho" poderia ser avaliada como verdadeira ou falsa (ANGIONI, 2006, p. 115).

No caso da frase $O$ não-ser humano é branco, a atribuição de verdade à sentença é bastante imprecisa, pois o que exatamente seria o não-ser humano?

A motivação de Aristóteles para a proposição dos nomes infinitos parece ser de natureza puramente lógica, em função da possibilidade formal da negação de um predicado. De fato, a negação, segundo Aristóteles, pode se dar nos dois constituintes da predicação: sujeito e predicado. Assim, a proposição "O justo é sábio", pode ser negada de duas formas: i. Não-justo é sábio"; ii. "O justo é nãosábio".

No capítulo 10 de De Interpretatione, Aristóteles argumenta que, a partir da proposição "Sócrates não é sábio", pode-se inferir que "Sócrates é não-sábio". Ou seja, para o filósofo grego, os nomes infinitos fazem parte de proposições com valor de verdade e que podem entrar em deduções lógicas. Nesse aspecto, os nomes infinitos são similares aos nomes genuínos. O que Aristóteles faz é propor nomes infinitos (como não-sábios), para capturar a dedução logicamente perfeita.

Mas ainda que um nome infinito possa entrar em uma proposição com valor de verdade, a sua estrutura semântica é diferente do nome genuíno. Um nome genuíno conota uma classe específica de seres; um nome infinito conota infinitas classes de seres. É interessante que a infinitude dessa conotação pode ser interpretada ao pé da letra: por exemplo, na classe dos não-seres humanos podem entrar tipos infinitos de coisas. A negação de um conceito deixa tudo em aberto, de um ponto de vista lógico, e também semântico. O meu ponto, neste artigo, é que, nas línguas humanas, quando se nega um predicado (ou um conceito), normalmente essa negação está contida num sistema conceitual que delimita a significação do predicado. Por exemplo, o conceito de não-governamental poderia conotar qualquer coisa que não fosse governamental, abstrata ou concreta, real ou imaginária, mas em línguas humanas se aplica, de forma mais restrita, a um certo tipo de organização social, as ONGs. O não é puramente contrastivo, nas línguas humanas, ao menos na função de criação de nomes. Talvez Aristóteles estivesse pensando em termos estritamente lógicos e não linguísticos, no caso dos nomes

\footnotetext{
${ }^{6}$ Esta frase é de Aristóteles, em Segundos Analíticos, tradução de Angioni, 2006, p. 184.
} 
infinitos. No caso das línguas humanas, a negação possibilita a delimitação de conceitos, e não a infinitude.

Aristóteles não dá muitas justificativas sobre por que expressões como não-ser humano seriam nomes infinitos. O uso de designações negativas é um procedimento comum na estruturação do léxico linguístico, e muitos pares de nomes são baseados numa oposição sim/não. Por exemplo, a oposição solteiro $x$ casado. O termo solteiro pode ser definido como não-casado. Portanto, nãocasado denota uma classe bem definida ${ }^{7}$, e não infinita. Da mesma forma, temos a oposição feras $x$ animais domesticados, o que gera a possibilidade de criar a classe das não-feras. Nesse caso, também, o termo não-fera seria uma classe bem delimitada, e não infinita. Da mesma forma, num estádio de futebol, temos a oposição entre time da casa x time visitante. Nesse caso, não-time da casa seria uma boa definição de time visitante. E como essas, há muitas outras oposições baseadas na negação. Então por que não-ser humano parece dispor de um estatuto particular?

Na seção 2, a seguir, vou discutir as razões que levam Aristóteles a propor que os nomes infinitos não são nomes genuínos. Na seção 3, mostro que, se passamos a entender que o significado é relacional, então a denominação não depende de uma ligação direta entre sentido e referência, mas de uma relação entre séries de significados que definem o que é a referência em determinados contextos.

\section{SEMÂNTICA E ONTOLOGIA NOS NOMES INFINITOS}

Para Aristóteles, não há uma separação entre os níveis semântico e ontológico. Há uma ambiguidade intrínseca no valor que Aristóteles atribui ao conteúdo de uma expressão linguística: esse conteúdo pode tanto se referir ao estado mental constituído pelo significado, ou seja, aquilo que o filósofo chama de afecções da alma, em De Interpretatione; como também pode se referir à própria coisa ou estado de coisas (o que o filósofo chama de pragma) à que o conteúdo da expressão se refere. Dessa forma, há uma ligação intrínseca entre conteúdo mental e pragma (DE RIJK, 2002, p. 65).

É possível separar estes dois elementos da significação - o mental e o referencial, considerando-as como duas condições da significação (MODRAK, 2001, p. 65): a primeira condição define a coerência conceitual do conteúdo de uma expressão; a segunda condição é a capacidade de uma expressão de manter uma relação de semelhança com um pragma. Um nome infinito, como não-ser humano, satisfaz a primeira condição, pois o termo é coerente e significativo, mas ele não é capaz de satisfazer a segunda condição, pois não se liga de forma definida a um pragma.

Para Aristóteles, a semântica é dependente da ontologia. Classes de seres naturais, com essências específicas, definem o que existe. Os seres humanos

\footnotetext{
${ }^{7}$ Pode incluir, além de solteiros, divorciados, separados, viúvos, etc, mas não é uma classe infinita.
} 
formam uma dessas classes. A ligação de um nome com essa classe de seres, por intermédio de um estado mental, define o sucesso denominativo da expressão ser humano. Ou seja, o uso do nome pressupõe o ser.

De fato, a significação do nome é causada pelo pragma. A significação do nome (o que modernamente chamaríamos o seu sentido) é o efeito na mente (pathema) causado por algum pragma (coisa ou estado de coisas). Assim, a significação é um efeito na mente causada por uma coisa que lhe é semelhante (CHARLES, 2000, p. 82). Aristóteles sugere, assim, uma relação necessária e natural entre o estado mental e a coisa que ele representa, um pouco como se o sentido fosse um tipo de analogia da coisa. Curiosamente, esta posição de Aristóteles evoca o naturalismo advogado por Crátilo, no diálogo platônico ${ }^{8}$. O sentido e a coisa são homólogos, o primeiro sendo um efeito da segunda.

Sendo assim, é impossível separar, na semântica aristotélica, o nome da coisa que ele denota, pois a significação é uma analogia da coisa. Ou seja, mesmo que isolemos o nome, separando-o da coisa, esta continua impregnada no nome. Dessa forma, fica mais claro entender por que os nomes infinitos não são genuínas denominações: eles não são analogias das coisas. E não são analogias porque a semântica de não- ser humano não define uma classe de coisas, não podendo, portanto, ser causada por ela. Se a significação de não- ser humano fosse causada por um pragma, seria uma perfeita denotação desse pragma. Mas há um número enorme (potencialmente infinito) de coisas candidatas a serem não- ser humano. Com isso, não há denominação, nem homologia entre nome e coisa.

Um outro elemento interessante da semântica de Aristóteles é que os efeitos que as coisas causam na mente "são os mesmos para todos, assim como são as mesmas coisas, das quais essas afecções são semelhanças” (De Interpretatione, tradução de ANGIONI, 2006, p. 178). As semelhanças entre nome e coisa são objetivas e não variáveis de falante para falante; um nome como ser humano satisfaz esta condição de objetividade, mas um nome como não- ser humano não satisfaz, pois não há uma semelhança, ou homologia, perceptível para todos os falantes. Dito de outra forma, a relação entre o nome ser humano e a coisa que ele representa é natural e objetiva; já a relação entre o nome não-ser humano e a coisa que ele representa não é natural, não sendo comum para todos (MODRAK, 2001, p. 19).

Em suma, a inexistência, nos nomes infinitos, de uma semelhança entre nome e coisa anula a função básica dos nomes, que é a de denotar "things as selfcontained, subsistent wholes" (DE RIJK, 2002, p. 60). Esses seres que subsistem são as famosas substâncias. A função dos nomes genuínos é denotar estas substâncias, com base na homologia entre significação e substância representada. Num universo composto por substâncias, a função da linguagem é a de uma nomenclatura, mas uma nomenclatura que traz à luz a essência de cada substância.

${ }^{8} \mathrm{O}$ fato é curioso, porque normalmente se atribui a Aristóteles uma posição convencionalista. De fato, ele é convencionalista em relação à ligação entre a palavra falada e a significação, mas naturalista na relação entre significação e referência (MODRAK, 2001, p. 19).

${ }^{9}$ Ousia é o termo usado por Aristóteles. 
Aristóteles era otimista sobre a capacidade de a linguagem representar a verdade, ao contrário de seu mestre, Platão, para quem a linguagem podia nos enganar quanto à verdade das coisas (MODRAK, 2001, p. 19).

A semântica aristotélica pressupõe uma relação direta entre um nome e uma coisa e isto o leva a negar uma função denominativa ao termo não-ser humano. Na seção seguinte, vou argumentar que, antes da relação entre nome e coisa, há uma relação semântica entre nome e nome. Este caráter relacional do nome é o que permite, em diferentes contextos, a determinação da referência.

\section{O CARÁTER RELACIONAL DOS NOMES E A DETERMINAÇÃO CONTEXTUAL DA REFERÊNCIA.}

A semântica aristotélica ${ }^{10}$ define que um nome está ligado, por uma relação causal, com a coisa que ele designa. A linguagem, nessa perspectiva, seria uma nomenclatura, ainda que uma nomenclatura de um tipo especial, em que há uma relação do tipo causa e efeito entre a coisa e o rótulo.

Saussure (s.d., p. 79), em passagem famosa, critica esta noção da linguagem como nomenclatura (embora ele não cite diretamente Aristóteles): "para certas pessoas, a língua, reduzida a seu princípio essencial, é uma nomenclatura, vale dizer, uma lista de termos que correspondem a outras tantas coisas (...).Tal concepção é criticável em numerosos aspectos."

Para Aristóteles, o termo não- ser humano não funciona como nome, basicamente porque não entra numa nomenclatura. Mas se a linguagem humana não é uma nomenclatura, então um nome infinito pode funcionar como um nome genuíno.

É interessante aqui examinar mais detidamente por que Saussure recusa a ideia da nomenclatura. Uma nomenclatura pressupõe que cada coisa seja percebida como uma entidade que possa ser identificada e descrita por meio de um rótulo. Assim, o termo ser humano seria um rótulo apropriado para descrever a identidade de uma determinada classe de coisas. Para Aristóteles, essa denominação se dá por meio de uma definição associada ao nome (no caso de ser humano, a definição seria 'animal bípede'), que captura a essência da coisa designada. Isso implica que não só a coisa, mas o nome tem uma delimitação clara de sua abrangência. Um nome evocaria uma definição positiva, indicando aquilo que a coisa é.

Saussure (2012, p. 70), no entanto, sugere que a significação positiva de uma palavra é insuficiente para capturar todos os aspectos relevantes de uma coisa: "a palavra só aborda o objeto material segundo uma ideia que é, ao mesmo tempo, totalmente insuficiente, se for considerada com relação a esse objeto, e infinitamente ampla, se for considerada fora do objeto".

Considere, por exemplo, a coisa que chamamos de casa. O nome casa, segundo Saussure (2012) não captura todos os aspectos relevantes da coisa

${ }^{10}$ Pode-se discutir se de fato Aristóteles tinha uma teoria semântica. Sigo Modrak, 2001, na admissão de que existe, ainda que não totalmente desenvolvida, uma semântica aristotélica. 
referida, pois as impressões que recebemos de uma coisa são as mais variadas, de modo que "em momento algum, a impressão que causa um objeto material tem o poder de criar uma única categoria linguística” (Saussure, 2012, p. 70).

Esta afirmação de Saussure poderia parecer indicar que ele é pessimista quanto à possibilidade de um nome designar as coisas. Mas, na verdade, ele está chamando a atenção sobre a impossibilidade de uma relação direta entre nome e coisa, pois esta relação seria ao mesmo tempo insuficiente, e ampla demais em relação ao conjunto de coisas.

A solução encontrada por ele é estipular que a significação completa de uma palavra (por exemplo, casa) só é definida com base na "co-existência de outros termos" (Saussure, 2012, p. 73). Em casa, várias relações entre termos são possíveis, gerando a criação de novos nomes, que especificam as diferentes oposições potenciais contidas na noção de casa. Dessa forma, a sinonímia é fruto da amplitude possivelmente infinita da noção associada a uma coisa. Uma casa pode ser "uma construção, um prédio, um edificio, (um monumento), um imóvel, uma habitação, uma residência" (Saussure, 2012, p. 70).

Para Saussure, o conceito associado a uma coisa só pode ser definido de forma negativa, ou seja, indicando-se aquilo que este conceito não é. E esta negatividade só pode ser capturada se existe uma co-existência de termos em contraste. Por exemplo, uma casa é um imóvel, e imóvel se opõe a bens móveis. Portanto, uma parcela da noção associada à coisa referida pelo signo casa é capturada pela oposição bem imóvel x bem móvel. Assim, casa pode ser definida, negativamente, como algo que não é um bem móvel ${ }^{11}$.

O termo residência, por sua vez, captura a noção de lugar de permanência constante e regular, o que gera a oposição possível entre residência $x$ hotel. $\mathrm{O}$ conceito de residência, por sua vez, gera a referência puramente negativa da expressão sem residência fixa ${ }^{12}$.

Podemos agregar o termo lar à série de sinônimos apresentada por Saussure. Um lar é um lugar de habitação regular visto sob uma ótica positiva. Uma habitação pode não ser um lar.

Em suma, para Saussure não faz sentido pensar em um conceito absoluto e positivo que exaure todos os aspectos de uma coisa. A nomenclatura se torna, dessa forma, um empreendimento impossível. Novas relações semânticas podem ser criadas. A criação de sinonímias, ou seja, a marcação de novas diferenças no âmbito de um mesmo campo conceptual, é um processo potencialmente infinito: "A sinonímia de uma palavra é, nela mesma, infinita, ainda que seja definida com relação a uma outra palavra" ((Saussure, 2012, p. 71)

Saussure propõe uma semântica relacional, na qual o sentido de um signo não é definido de forma absoluta, mas com base em uma série de relações com outros

\footnotetext{
${ }^{11}$ Aristóteles, se pudesse, talvez replicasse que bem imóvel é uma categoria diferente de casa, sendo superordenada em relação a ela.

${ }^{12}$ Em inglês, há o termo homeless para indicar as pessoas sem residência fixa. Em francês, usase a expressão SDF, (sans domicile fixe), para indicar o mesmo tipo de situação. Quer dizer, as línguas podem dispor de nomes ou perífrases para marcar as oposições relevantes.
} 
termos. Isso vale mesmo para termos cuja definição é em tese positiva, como casa ou ser humano. As diferentes significações desses nomes são potencialmente infinitas, pois dependem das relações semânticas a serem estabelecidas pela coexistência de termos.

Apliquemos, agora, esta ferramenta de correlação entre termos aos nomes infinitos de Aristóteles. Com base em uma relação semântica específica, o nome não-ser humano pode adquirir um significado específico. Por exemplo, não-ser humano pode significar ET, numa oposição entre ETs x terráqueos. O nome nãoser humano pode significar também ser dotado de inteligência de natureza não biológica, na oposição entre robôs $x$ seres humanos.

Uma teoria semântica relacional, a meu ver, equivale a uma teoria contextual da significação. Quero dizer com isso que o termo não- ser humano ganha um sentido e uma denotação definidos quando usado num contexto de relações semânticas específicas: não- ser humano pode simplesmente significar ET, num contexto em que a oposição ETs $x$ terráqueos seja evocada.

Em suma, a significação de um termo como não-ser humano é potencialmente infinita, mas se torna perfeitamente definida num contexto específico.

Saussure focou sua atenção nas oposições semânticas efetivamente codificadas no léxico de uma língua. Por outro lado, autores contextualistas (SPERBER; WILSON, 1986; CARSTON, 2002; RECANATI, 2004) chamam a atenção para o fato de que a denotação de qualquer termo só é efetivamente definida no plano dos enunciados, ou seja, quando uma proposição é proferida num determinado contexto de uso. Para os contextualistas, o estado de coisas referido por uma proposição só pode ser especificado quando a proposição é interpretada num contexto. Vejamos, por exemplo, a frase abaixo:

\section{1) Eu quero café.}

O nome café pode denotar uma enormidade de coisas diferentes. Pode significar grãos de café, café em pó, litros de café, uma xícara de café coado, um café expresso, etc. A denotação do nome café só poderá ser definida no contexto de uso da frase (1), levando-se em conta as intenções do falante ao proferir a frase. Isso implica que mesmo nomes com possíveis definições positivas também possuem uma denotação indefinida, e que a definitude da referência só é obtida depois que se tem acesso ao contexto relevante. Os nomes devem passar por um processo de enriquecimento pragmático (CARSTON, 2002), o qual provê as informações relevantes, para que a denominação seja eficaz.

A meu ver, as relações semânticas de Saussure e o enriquecimento pragmático dos contextualistas são duas formas de reduzir a amplitude referencial de um nome. Por exemplo, na interpretação de (1), podemos fazer uso de termos já estruturados no sistema lexical da língua portuguesa, ou então podemos recorrer a conceitos puramente contextuais e ainda não codificados na língua.

Na frase Eu quero café, podemos interpretar que o falante deseja café puro, em oposição a leite, ou então que ele deseja café no leite. Para expressar essas oposições, a língua portuguesa dispõe da palavra média, que é café com leite. Ou 
seja, em um dos contrastes semânticos possíveis, o nome café se opõe ao nome média, sendo outra oposição possível caféx leite. Na frase (1), o falante pode estar se referindo a café no leite (média), ou a café sem leite. No segundo caso, café significaria não-leite. Esses contrastes semânticos são corriqueiros e facilmente acessíveis por meio dos itens lexicais que os codificam.

Mas há toda uma série de distinções que não são lexicalizadas. Por exemplo, seria muito estranho que a frase Eu quero café, dita num restaurante, fosse interpretada como um pedido de um barril de café frio. A definição da denotação de um nome é sempre o resultado de uma sintonia fina entre o que é dito e o contexto no qual o que é dito surge.

Assim, as oposições semânticas estudadas por Saussure são apenas uma parte das restrições contextuais a que um nome está sujeito. Muitas delimitações contextuais funcionam dentro de um frame específico, não lexicalizado, ou de maneira $a d$ hoc. Conceitos ad hoc são aqueles que emergem, de forma provisória, para fins específicos (CARSTON, 2002). Um exemplo seria o conceito de tudo aquilo que devemos salvar prioritariamente em um incêndio. $\mathrm{O}$ conceito de nãoser humano, igualmente, pode ser definido de uma forma ad hoc. Se da minha janela eu não vejo nenhum ser humano, eu posso definir o não-ser humano como aquilo que vejo de minha janela.

Conceitos ad hoc podem se estabilizar e ganhar um valor semântico mais permanente em determinados contextos. Por exemplo, na teoria transumanista, o conceito de pós-humano corresponde a uma definição do conceito de não-ser humano. O pós-humano, nessa teoria, corresponde a uma categoria de seres que derivam do ser humano, mas que o 'superaram', em função do avanço tecnológico. Trata-se, portanto, de uma definição que delimita o conceito de não- ser humano.

Outra possibilidade ocorre quando a denotação é indicada verbalmente, por meio de um conjunto de descrições, embora não exista uma palavra específica para esta denominação visada. É o caso do exemplo abaixo, que o usa o termo not human: "Everything that comes within thirty feet of our houses that's alive and not human dies. It's like a curse". (FRANKEL, 2013, p. 45)

Neste caso, o termo not human denota a fauna e a flora, com exclusão dos seres humanos. Aqui, claramente, o predicado indefinido not human se torna definido, no contexto da descrição verbal.

\section{CONCLUSÃO}

Neste artigo, propus que a denotação dos nomes infinitos pode se tornar definida por meio de recursos contextuais. Esses recursos podem ser relações semânticas entre nomes, ou enriquecimentos inferenciais com base no contexto de enunciação. Dessa forma, não há distinção entre nomes infinitos e nomes genuínos, pois ambos estão sujeitos aos mesmos procedimentos de variação contextual.

É interessante notar que a solução contextual para os nomes infinitos já parece disponível na própria semântica aristotélica. Uma predicação como Deus é não-ser humano é válida e pode receber um valor de verdade. Com base nela, 
pode-se inferir que o termo não-ser humano abarca Deus (ou deuses), tornando-se, destarte, um termo definido no contexto dessa predicação.

De Rijk (2002, p. 206, nota 61) observa que, quando usado em uma asserção, o nome infinito ganha uma denotação definida, como em "This not-man is a tree". Nesse caso, o contexto da própria sentença delimita a denotação do nome indefinido. Essa sentença pode ser representada por meio da forma lógica $x$ é nãoser humano e x é árvore. Nesse caso, o subjacente (hypokeimenon) é bem definido, correspondendo ao $x$.

Também no caso em que o nome infinito é delimitado por um conjunto de descrições, como no caso do trecho citado acima ("Everything that comes within thirty feet of our houses that's alive and not human dies"), é possível definir a denotação com base na conjunção de duas propriedades, que são predicadas do mesmo ser: $x$ tem vida e $x$ é não humano. Essa fórmula implica que algo que tem vida, é também não humano, o que define um uso específico do predicado não humano. No caso da citação, este algo que tem vida e é não humano, termina morrendo.

O problema não parece ser, portanto, a interpretação contextual dos nomes infinitos, mas a própria semântica dos nomes genuínos, em Aristóteles. Um nome genuíno, como vimos, é aquele que, na semântica de Aristóteles, estabelece uma conexão direta com a coisa designada, por meio de uma relação causal. Não faz sentido, na semântica aristotélica, atribuir um papel ao contexto na denotação dos nomes genuínos, pois o sentido de um nome como ser humano é o efeito da ação da coisa sobre este nome, e isto não depende de qualquer contexto.

Por outro lado, na semântica contextualista, a relação entre o nome e a coisa não é direta, mas intermediada por um contexto. A relação simbólica que leva do sentido à referência é ternária (nome, palavra, contexto) e não binária (nome, coisa), tanto no caso dos nomes infinitos, como no caso dos nomes genuínos.

\section{REFERÊNCIAS BIBLIOGRÁFICAS}

ANGIONI, L. Introdução à teoria da predicação em Aristóteles. Campinas: Ed. UNICAMP, 2006.

BOETHIUS. On Aristotle On interpretation. London: Bloomsbury, 2011.

CARSTON, R. Thought and Utterances: the Pragmatics of Explicit Communication. Oxford: Blackwell, 2002.

CHARLES, D. Aristotle on meaning and essence. Oxford: Clarendon Press, 2000.

DE RIJK, L. M. Aristotle. Semantics and ontology. Vol 1. Leiden: Brill, 2002.

MADER, G; MOURA, H. O masculino genérico sob uma perspectiva cognitivo-funcionalista. Revista do GELNE. Vol 17, 2015, p. 33-54.

FRANKEL, J. The red ring. Toronto: Xeno Publications, 2013.

JONES, R. B. The Organon: The Works of Aristotle on Logic. London, RB Jones Editions, 2012. 
MODRAK, D. Aristotle's theory of language and meaning. Cambridge: Cambridge University Press, 2001 .

RECANATI, F. Literal Meaning. Cambridge: Cambridge University Press, 2004.

SAUSSURE, F. de. Curso de Linguística Geral. 11. ed. São Paulo: Cultrix, s/d. (original de 1915).

SAUSSURE, F. Escritos de Linguística Geral. São Paulo: Cultrix, 2012.

SPERBER, D; WILSON, D. Relevance. Oxford: Blackwell, 1986.

WHITAKER, C.W.A. Aristotle's De interpretatione. Contradiction and dialectic. Oxford: Clarendon Press, 1996.

Recebido: 16/02/2017

Aceito: 21/03/2017 